\title{
Vestibular Exercises as a Fall Prevention Strategy in Patients with Cognitive Impairment
}

\author{
Brenda Varriano (D), Shaleen Sulway, Curtis Wetmore, Wanda Dillon, \\ Karen Misquitta, Namita Multani, Cassandra Anor, Maria Martinez, \\ Elena Cacchione, John Rutka, Maria Carmela Tartaglia
}

\begin{abstract}
Vestibular impairment (VI) and cognitive impairment (CI) are risk factors for senior falls. We tested the feasibility of a self-directed 12-week vestibular rehabilitation (VR) program in Memory Clinic patients (65 years+) with a fall, CI and VI. We assessed recruitment, exercise adherence and ability to complete questionnaires/assessments. Twelve patients with CI and falls were screened and 8/12 (75\% - prevalence) had VI. All patients completed the screening tests/questionnaires (100\% - completeness); $7 / 8$ patients were recruited $(87.5 \%$ - recruitment); $1 / 7$ (85.7\% - attrition) patient attended follow-up. VI is prevalent in patients with CI experiencing falls but traditional VR is not feasible, so a novel delivery of VR must be explored.

RÉSUMÉ: Les exercices de réadaptation vestibulaire comme stratégie de prévention des chutes chez des patients atteints de troubles cognitifs. Les troubles vestibulaires (TV) et les troubles cognitifs (TC) sont des facteurs de risque de chute chez les personnes âgées. À cet égard, nous avons évalué le caractère réalisable d'un programme autonome de réadaptation vestibulaire de 12 semaines offert, dans une clinique de la mémoire, à des patients âgés de 65 ans et plus ayant chuté au moins une fois et qui sont atteints de TV et de TC. Nous nous sommes ainsi penchés sur leur recrutement, leur adhésion aux exercices du programme et leur capacité à compléter des questionnaires d'évaluation. Douze patients aux prises avec des TC ont été examinés. De ce nombre, huit d'entre eux (75\%) étaient aussi atteints de TV. Tous ces patients ont complété des tests de dépistage ainsi que des questionnaires, lesquels ont été remplis dans $100 \%$ des cas. Au total, sept patients sur huit ont été recrutés, soit 87,5\%, tandis qu'un seul, ce qui représente un taux d'attrition de 85,7 \%, s'est présenté lors d'un suivi. Même si les TV affectent les patients atteints de TC, un programme de réadaptation vestibulaire n'est pas réellement réalisable dans ce contexte, de sorte qu'un nouveau programme devrait être exploré.
\end{abstract}

Keywords: Falls, Cognitive decline, Vestibular diseases, Rehabilitation research

Abbreviations: ABC - Activities-specific balance confidence scale; AD - Alzheimer's dementia; BPPV - Benign paroxysmal positional vertigo; DGI - Dynamic gait index; DHI - Dizziness handicap inventory; DVI - Definite vestibular impairment; GDS - Geriatric depression scale; HIT - Head impulse test; mCTSIB - Modified clinical test of sensory interaction on balance; MCI - Mild cognitive impairment; MoCA - Montreal cognitive assessment; NVI - No vestibular impairment; PETS - Problematic experiences of therapy scale; PVI - Probable vestibular impairment; QOL-AD - Quality of life Alzheimer's disease; VAD - Vascular dementia; VOR - Vestibuloocular reflex; WHOQOL-BREF - World Health Organization Quality of Life BREF

doi:10.1017/cjn.2019.309

Can J Neurol Sci. 2020; 47: 126-130

Falls are a growing concern in seniors $(\geq 65$ years $) .{ }^{1}$ Cognitive decline $^{1}$ and vestibular impairment (VI) increase with age and are correlated with an increased risk of falling. ${ }^{2}$ Vestibular rehabilitation (VR) is used to treat $\mathrm{VI}^{3}{ }^{3}$

We tested the feasibility of a VR program in Memory Clinic patients with previous falls. The aim of this study was to assess the feasibility of recruitment, ability to complete screening tests/ questionnaires, feasibility of the program and compliance to a VR program in patients with mild cognitive decline and VI.

Patients who had attended the Memory Clinic and were $\geq 65$ years of age, English speaking, had a diagnosis of MCI/AD/VaD/ mixed dementia, ${ }^{4-7}$ fell within the past year and able to provide consent were contacted. Exclusion criteria consisted of additional neurological disease (i.e. seizures or stroke), severe psychiatric disease, current inner-ear infection, severe neck arthritis, Montreal cognitive assessment (MoCA) score $<15$ or $>26$ (v7.1) ${ }^{8}$ or other aetiology of dementia (i.e. Parkinson's disease). Eligible patients

From the Faculty of Medicine, Tanz Centre for Research in Neurodegenerative Diseases, University of Toronto, Toronto, Ontario, Canada (BV, KM, NM, CA, MCT); Hertz Multidisciplinary Neurotology Clinic, Toronto General Hospital, Toronto, Ontario, Canada (SS, WD, JR); Centre for Advanced Hearing and Balance Testing, Toronto General Hospital, Toronto, Ontario, Canada (CW); Memory Clinic, Toronto Western Hospital, Toronto, Ontario, Canada (MM, EC, MCT); Department of OtolaryngologyFaculty of Medicine, University of Toronto, Toronto, Ontario, Canada (JR); Krembil Neuroscience Centre, Toronto Western Hospital, Toronto, Ontario, Canada (MCT)

Received July 23, 2019. Final Revisions Submitted September 12, 2019. Date of Acceptance October 7, 2019.

Correspondence to: Carmela Tartaglia, University of Toronto, Toronto Western Hospital, 399 Bathurst St. WW5-449, Toronto, Ontario M5T 2S8, Canada. Email: carmela.tartaglia@uhn.ca 


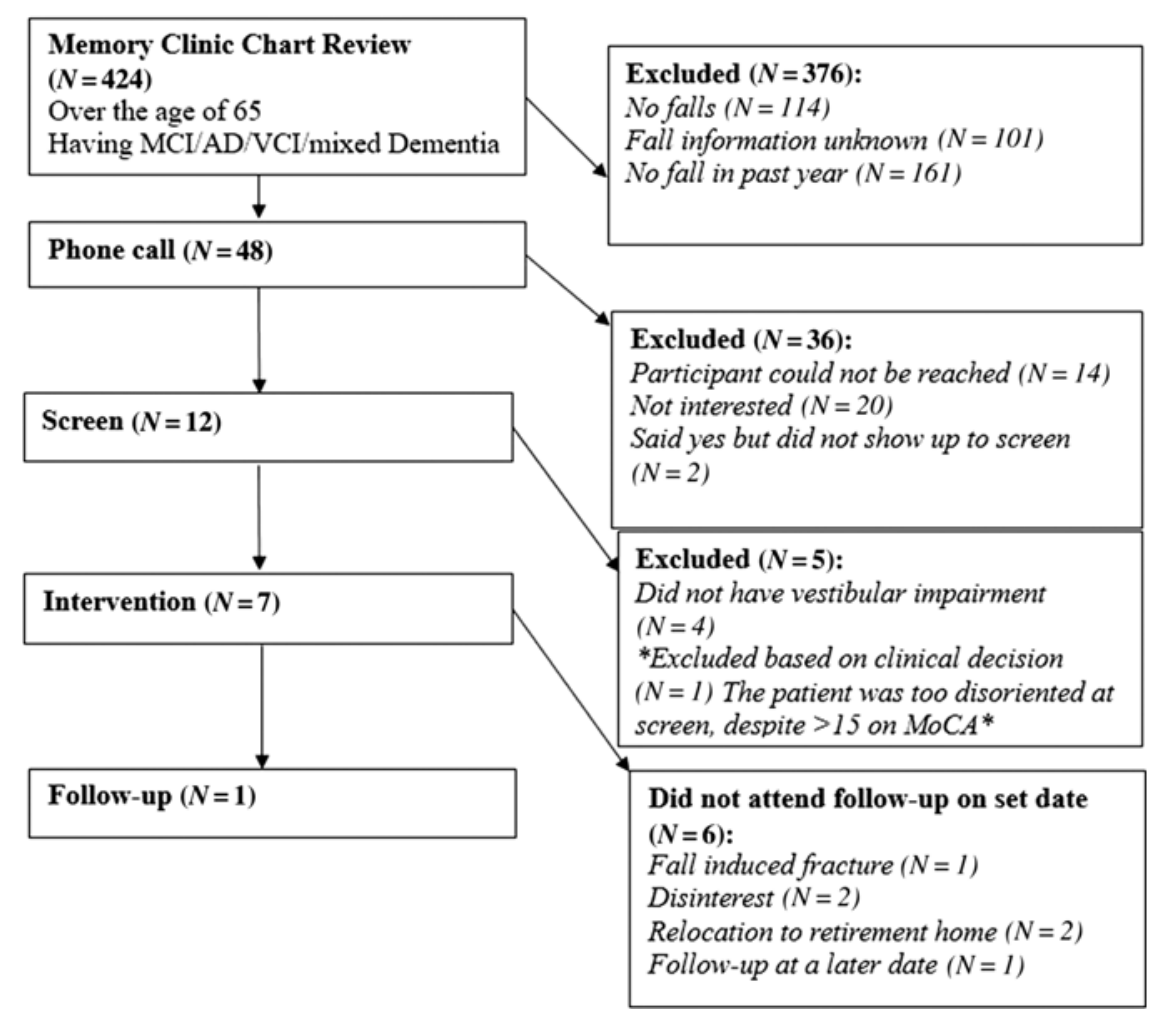

Figure 1: Patient flow throughout course of study.

were called (1 message/patient) and invited to a screen for VI. The MoCA, dizziness-handicap inventory (DHI) and activities-specific balance confidence scale (ABC) were administered for cognitive state, levels of perceived dizziness and confidence in performing daily activities without losing balance, respectively. VI was assessed using the Dix-Hallpike test, ${ }^{9}$ both the bedside- and video head impulse test (HIT and vHIT), ${ }^{10}$ the Headshake test (HST) ${ }^{11}$ and the modified clinical test of sensory interaction on balance (mCTSIB). ${ }^{12}$

Definite vestibular impairment (DVI) was diagnosed if patient failed Dix-Hallpike, HIT/vHIT or HST. Failure of mCTSIB alone was diagnostic of probable VI (PVI), unless failed additional test, in which the patient would be categorized as having a DVI. Patients were diagnosed with unilateral vestibular hypofunction (UVH) if there was an abnormal test result on one side or bilateral vestibular hypofunction (BVH) if both sides were affected.

Those with VI went on to baseline assessment including the dynamic gait index (DGI) for gait, geriatric depression scale (GDS) for depression and both the WHOQOL-BREF and QOL-AD for quality of life. Patients were then randomized to a VR or control-arm $(\mathrm{CON})$ via a coin toss.

Patients in the VR arm were assigned 12 weeks of exercises, whereas patients in CON continued with standard care (no exercise program). Twelve weeks later, patients returned and retested for changes from baseline (ABC, DHI, DGI, WHOQOLBREF and QOL-AD). In addition, patients were given the Problematic Experiences of Therapy Scale (PETS). The PETS was used to gauge barriers to VR adherence. ${ }^{13}$ At 24 weeks, patients were called to ask if any falls occurred.

Participants in the VR arm performed vestibular exercises 3 times daily, 3-10 minutes/session (see Supplementary Materials).
Exercises progressed every 2 weeks. Patients were called biweekly to monitor compliance.

Feasibility metrics included: prevalence of DVI, recruitment of patients screened to intervention, compliance to exercises, attrition during the intervention period and ability of participants to complete the questionnaires. Feasibility criteria were set at: a recruitment rate of $45 \%,{ }^{14}$ compliance rate as ability to carry out $60 \%$ of the exercises, ${ }^{15}$ attrition rate of $30 \%$ or less ${ }^{15}$ and $60 \%$ of participants to complete a given questionnaire in its entirety. ${ }^{16}$

Flow of patients is shown in Figure 1. There were 424 patients over the age of 65 with MCI/early dementia; $209 / 424$ (49.3\%) had experienced a prior fall, 114/424 (26.9\%) had no falls and in 101/424 (23.8\%) fall history unknown (Supplementary Table 1). Of 209, 48 participants experienced a fall within the past year and met inclusion criteria (Supplementary Table 2). Of 48, 34 $(70.8 \%)$ patients were contacted by phone; $14 / 34(41.2 \%)$ agreed to participate in the study. Of 14,12 (85.5\%) participants attended screening. Screening results are given in Table 1. Mean age of those screened was $77.3 \pm 6.7$ years old and 8/12 $(66 \%)$ were men. Of $12,8(75.0 \%)$ of screened participants were diagnosed with a DVI. Of those with DVI, 4/8 (50.0\%) had UVH and 4/8 (50.0\%) had BVH. Of 12, 1 participant had PVI due to failure of the mCTSIB alone and 3/12 (25.0\%) had no vestibular impairment (NVI). Abnormal vestibular test results are given in Table 2, and mCTSIB results are given in Supplementary Table 1 .

The mean MoCA score was $21.2 \pm 2.9$ for the DVI group, 23.0 for the one participant with PVI and $24.7 \pm 1.5$ for those with NVI. One participant with DVI that had been randomized to the intervention arm did not complete the MoCA due to time constraint. 
Table 1: Screening questionnaire results at a Memory Clinic in those with and without vestibular impairment $(N=12)$

\begin{tabular}{l|c|c|c}
\hline Assessment & DVI $(\boldsymbol{N = 8})$ & PVI $(\boldsymbol{N = 1})$ & NVI $(\boldsymbol{N = 3})$ \\
\hline Age (years) & $79.8 \pm 6.5$ & 70 & $73 \pm 4.6$ \\
\hline Sex (M:F) & $4: 4$ & $1: 0$ & $3: 0$ \\
\hline MoCA $(/ 30)$ & $21.2 \pm 2.9$ & 23.0 & $24.7 \pm 1.5$ \\
\hline DHI (/100) & $13.8 \pm 16.1$ & 4.0 & $4.7 \pm 5.0$ \\
\hline ABC $(\%)$ & $69.2 \pm 29.6$ & 89.4 & $89.8 \pm 1.8$ \\
\hline
\end{tabular}

$\mathrm{ABC}=$ activities-specific balance confidence scale; $\mathrm{DHI}=$ dizziness handicap inventory; DVI = definite vestibular impairment; $\mathrm{MoCA}=$ Montreal cognitive assessment; $\mathrm{NVI}=$ no vestibular impairment; $\mathrm{PVI}=$ probable vestibular impairment.

Table 2: Abnormal tests of vestibular functioning at a Memory Clinic $(N=8)$

\begin{tabular}{l|l|c|l}
\hline Assessment & & Prevalence (\%) & \multicolumn{1}{c}{ Diagnosis } \\
\hline Dix-Hallpike test & Positive & $1 / 8(12.5)$ & BPPV \\
\hline $\begin{array}{l}\text { Video head } \\
\text { impulse test }\end{array}$ & Unilateral & $3 / 8(37.5)$ & Unilateral VOR loss \\
\hline & Bilateral & $3 / 8(37.5)$ & Bilateral VOR loss \\
\hline Head impulse test & Unilateral & $3 / 8(37.5)$ & Unilateral VOR loss \\
\hline & Bilateral & $4 / 8(50.0)$ & Bilateral VOR loss \\
\hline mCTSIB & Fail & $8 / 8(100)$ & $\begin{array}{l}\text { Probable vestibular } \\
\text { loss }\end{array}$ \\
\hline Headshake test & Positive & $1 / 8(12.5)$ & Nystagmus \\
\hline
\end{tabular}

$\mathrm{BPPV}=$ benign paroxysmal positional vertigo; $\mathrm{VOR}=$ vestibulo-ocular reflex.

Those with DVI reported lower confidence scores on the ABC (69.2 \pm 29.6$)$, compared to the participant with PVI (89.4) and to those with NVI $(89.8 \pm 1.8)$. One quarter $(2 / 8)$ of participants had an $\mathrm{ABC}$ score lower than $67 \%$, indicating fall risk.

There was greater reported dizziness on the DHI in those with DVI $(13.8 \pm 16.1)$ compared with the participant with PVI who scored a 4.0 and those with NVI $(4.7 \pm 5.0)$, respectively. Overall, for the participant with PVI and those with NVI, there was a mild perceived handicap due to dizziness (score 0-30). Of those with DVI, 2/8 (25\%) had a moderate perceived handicap due to dizziness (score 31-60) and 6/8 (75\%) had a mild handicap due to dizziness (0-30).

Of eight, seven $(87.5 \%)$ participants with DVI continued onto the baseline assessment ( $87.5 \%$ recruitment rate). Those with PVI and NVI did not proceed to the next portion of the study. One participant did not continue to baseline because of decreased capacity to perform the exercises. All assessments and questionnaires in the baseline assessment were completed in their entirety (Table 3).

Mean DGI (gait) score was $18.9 \pm 3.0$. The DGI score was $<19$ in $5 / 7$ (71.4\%) participants, indicating that most participants were at risk for falls. Mean GDS (depression) score was
Table 3: Results from baseline assessment for those with definite vestibular impairment $(N=7)$

\begin{tabular}{|c|c|c|}
\hline \multicolumn{2}{|l|}{ Test } & DVI \\
\hline \multicolumn{2}{|l|}{ Age (years) } & $79.1 \pm 6.7$ \\
\hline \multicolumn{2}{|l|}{$\operatorname{Sex}(\mathrm{M}: \mathrm{F})$} & $3: 4$ \\
\hline \multicolumn{2}{|l|}{ DGI (/24) } & $18.9 \pm 3.0$ \\
\hline \multicolumn{2}{|l|}{ GDS (/30) } & $8.3 \pm 3.0$ \\
\hline \multicolumn{2}{|l|}{ QOL-AD (/52) } & $40.2 \pm 4.1$ \\
\hline \multirow{4}{*}{$\begin{array}{l}\text { WHOQOL BREF } \\
\text { (transformed scores) }\end{array}$} & Physical (/100) & 69 \\
\hline & Psychological (/100) & 69 \\
\hline & Environment (/100) & 75 \\
\hline & Social (/100) & 81 \\
\hline
\end{tabular}

QOL-AD = Alzheimer's disease quality of life; DGI = dynamic gait index; GDS = geriatric depression scale; WHOQOL-BREF $=$ world health organization quality of life BREF.

$8.3 \pm 3.0$, indicating no depressive symptoms. Only $2 / 7$ (28.6\%) of participants had a score of 10-19, indicating mild depressive symptoms. Mean QOL-AD score was $40.3 \pm 4.1$ for those with VI. Mean transformed WHO-QOL scores were 69 in the physical domain, 69 in the psychological domain, 75 in the environmental domain and 81 in the social domain, indicating good QOL.

Seven participants with DVI were randomized to the VR [5/7 (71.4\%)] or CON [2/7 (28.6\%)] arm. During the 12-week intervention period, $3 / 7$ participants dropped out; one participant (VR) dropped out due to a fall with hip fracture in week 1 (Supplementary Table 5). Two participants (1 VR and 1 CON) dropped out at the 6-week mark because of disinterest. The remaining four participants continued their respective arms for 12 weeks (3 VR and $1 \mathrm{CON}$ ). One participant (VR) fell at week 7. Of those in the VR arm, bi-weekly phone calls indicated no reported difficulties carrying out the exercises.

Four participants originally agreed to attend the 12-week follow-up; however, only two attended: one participant from the arm control attended follow-up on the set date, and one participant from the intervention arm attended follow-up at a later date due to a flu. The remaining two participants could not attend follow-up due to relocation into a retirement home. Overall, there was a $71.4 \%$ attrition rate and retention in rehabilitation was not feasible. Questionnaire/assessment completeness was $100 \%$ at follow-up (Table 4).

The participant from CON (VS_04) was able to complete all questionnaires upon return. This participant showed an increase in dizziness (DHI-10 from 2), impaired gait (DGI-17 from 19) and more depressive symptoms (GDS-12 from 8) compared to baseline. Interestingly, she showed a higher level of perceived confidence (ABC-87.8\% from 80.0\%) compared to baseline assessment and showed no significant change in QOL. One intervention participant (VS_01) attended follow-up 15 weeks after baseline. Overall, levels of dizziness decreased (DHI-30 from 32) but were still high. There was a large increase in confidence (ABC-85.3\% from 53.4\%) in ability to complete activities without loss of balance, which was clinically significant (>10\% change). ${ }^{17}$ DGI was 21 (from 22) and was not considered 
Table 4: Follow-up assessment results for participant VS_01 (Intervention) and VS_04 (control)

\begin{tabular}{|c|c|c|c|c|c|}
\hline \multicolumn{2}{|l|}{ Assessment } & \multirow{2}{*}{$\begin{array}{c}\text { VS_04 control baseline } \\
2 \\
\end{array}$} & \multirow{2}{*}{$\begin{array}{c}\text { VS_04 control FU } \\
10 \\
\end{array}$} & \multirow{2}{*}{$\begin{array}{c}\begin{array}{c}\text { VS_01 intervention } \\
\text { baseline* }\end{array} \\
32\end{array}$} & \multirow{2}{*}{$\begin{array}{c}\text { VS_01 intervention } \mathbf{F U} \text { * } \\
30 \\
\end{array}$} \\
\hline DHI & Total (/100) & & & & \\
\hline $\mathrm{ABC}$ & $\%$ Confidence & 80.0 & 87.8 & 53.4 & 85.3 \\
\hline \multicolumn{2}{|l|}{ DGI (/24) } & 19 & 17 & 22 & 21 \\
\hline \multicolumn{2}{|l|}{ GDS (/30) } & 8 & 12 & 13 & 10 \\
\hline \multicolumn{2}{|l|}{ QOL-AD (/52) } & 34 & 39 & 38 & 44 \\
\hline \multirow{4}{*}{$\begin{array}{l}\text { WHOQOL-BREF } \\
\text { (transformed scores) }\end{array}$} & Physical (/100) & 88 & 81 & 69 & 69 \\
\hline & Psychological (/100) & 69 & 69 & 69 & 69 \\
\hline & Environmental (/100) & 94 & 88 & 75 & 94 \\
\hline & Social (/100) & 31 & 44 & 100 & 94 \\
\hline
\end{tabular}

$\mathrm{ABC}=$ activities-specific balance confidence scale; $\mathrm{QOL}-\mathrm{AD}=$ quality of life Alzheimer's disease; DGI = dynamic gait index; DHI = dizziness handicap inventory; GDS = geriatric depression scale; WHOQOL = world health organization quality of life.

*The Intervention participant was unable to meet at the 12-week mark and was assessed 15 weeks post-baseline.

at risk for falls. Likewise, there was an increase in some QOL measures on the QOL-AD (44 from 38), WHOQOL-BREF (Physical-69 was same, Psychological-69 was same, Environmental-94 from 75, Social-94 from 100) and a slight decrease in levels of depression (GDS-10 from 13).

The control patient improved on the mCTSIB from baseline. At baseline, this participant was unable to complete condition three or four but upon return, they were able to complete condition three, but not four, suggesting a vestibular contribution to imbalance. Participant VS_01 was able to complete all three conditions, which was unchanged from baseline. VS_01 reported on the PETS that the obstacles to therapy were that exercises occasionally made symptoms worse and that it was difficult to remember to perform exercises. Compliance could not be recorded as VS_01 had forgotten to fill out the log, despite the phone calls. At 24 weeks, both the control (VS_04) and VR participant (VS_01) were contacted by telephone and neither had experienced a fall since the 12-week follow-up.

The self-directed VR protocol used in this study was not feasible for participants with both CI and VI. Few patients attended the screen; however, once participants were aware of a VI, they were easily recruited. Adherence to self-monitored VR could not be assessed and better methods of monitoring must be implemented into future trials. In addition, while not all participants completed the entire 12 weeks of the program, a majority remained in the study until the 6-week mark, suggesting that 6-week programs may be more feasible to complete. All assessments and questionnaires were completed at baseline and follow-up.

Overall, our results suggest that VI is common in those with $\mathrm{CI}$ and falls but that a modified VR program needs to be developed for participants with both CI and VI. A VR program that includes regular in-person monitoring or a group exercise program may be more beneficial for this patient population. This would allow for better compliance and assessment of technique in performing the exercises. Other contributors to falls including medication use and systemic illnesses need to be considered. Falls are multifactorial in nature, and therefore, it is critical to address all contributors to fall risk.

\section{ACKNOWLEDGEMENTS}

We would like to thank all patients and caregivers who participated in this study. We thank our colleagues from the Toronto General ENT clinic. We thank Dr. Naglie and Dr. Mansfield, who provided insight and expertise that greatly assisted the research.

\section{Funding}

This work has been supported by the following graduate awards and travel grants: Krembil Studentship in Dementia Research, Toronto General/Western Hospital Foundation Grant, Unilever Fellowship in Neurosciences, Alzheimer's Association Travel Fellowship and SGS Travel Grant.

\section{CONFlict of InTERests}

The authors declare that they have no competing interests.

\section{Statement of Authorship}

BV designed the study and collected data, in addition to preparation of the manuscript. SS, CW, and WD assisted with the vestibular assessments and interpretation of the study. JR and MCT are PI, who contributed staff and guidance in the study. $\mathrm{NM}, \mathrm{KM}$, and CA assisted with questionnaires at the baseline assessment. MM and EC assisted with recruitment of patients. All authors have read and approve the manuscript.

\section{Ethics Approval and Consent to Participate}

The Research Ethics Board of the University Health Network approved the study. Written consent was obtained from all subjects, as outlined by the University Health Network research protocol.

\section{SuPPLEMENTARY MATERIAL}

To view supplementary material for this article, please visit https://doi.org/10.1017/cjn.2019.309 


\section{REFERENCES}

1. Stinchcombe A, Kuran N, Powell S. Report summary. Seniors' falls in Canada: second report: key highlights. Chronic Dis Inj Can. 2014;34(2-3):171-4.

2. Agrawal Y, Carey JP, Della Santina CC, Schubert MC, Minor LB. Disorders of balance and vestibular function in US adults: data from the National Health and Nutrition Examination Survey, 2001-2004. Arch Intern Med. 2009; 169(10):938-44.

3. Herdman SJ. Vestibular rehabilitation. Curr Opin Neurol. 2013;26(1): 96-101.

4. Albert MS, DeKosky ST, Dickson D, et al. The diagnosis of mild cognitive impairment due to Alzheimer's disease: recommendations from the National Institute on Aging-Alzheimer's Association workgroups on diagnostic guidelines for Alzheimer's disease. Alzheimers Dement. 2011;7(3):270-9.

5. Gorelick PB, Scuteri A, Black SE, et al. Vascular contributions to cognitive impairment and dementia: a statement for healthcare professionals from the American Heart Association/American Stroke Association. Stroke. 2011;42(9):2672-713.

6. McKhann GM, Knopman DS, Chertkow H, et al. The diagnosis of dementia due to Alzheimer's disease: recommendations from the National Institute on Aging-Alzheimer's Association workgroups on diagnostic guidelines for Alzheimer's disease. Alzheimers Dement. 2011;7(3):263-9.

7. Rockwood K, Macknight C, Wentzel C, et al. The diagnosis of "mixed" dementia in the Consortium for the Investigation of Vascular Impairment of Cognition (CIVIC). Ann N Y Acad Sci. 2000;903(1):522-8.

8. Nasreddine ZS, Phillips NA, Bedirian V, et al. The Montreal Cognitive Assessment, MoCA: a brief screening tool for mild cognitive impairment. J Am Geriatr Soc. 2005;53(4): 695-9.

9. Dix MR, Hallpike CS. The pathology, symptomatology and diagnosis of certain common disorders of the vestibular system. Ann Otol Rhinol Laryngol. 1952;61(4):987-1016.

10. MacDougall H, Weber K, McGarvie L, Halmagyi G, Curthoys I. The video head impulse test Diagnostic accuracy in peripheral vestibulopathy. Neurology. 2009;73(14):1134-41.

11. Hain TC, Fetter M, Zee DS. Head-shaking nystagmus in patients with unilateral peripheral vestibular lesions. Am J Otolaryngol. 1987;8(1):36-47.

12. Cohen H, Blatchly CA, Gombash LL. A study of the clinical test of sensory interaction and balance. Phys Ther. 1993;73(6):346-51; discussion 51-4.

13. Kirby S, Donovan-Hall M, Yardley L. Measuring barriers to adherence: validation of the problematic experiences of therapy scale. Disabil Rehabil. 2014;36(22):1924-9.

14. Cooper C, Ketley D, Livingston G. Systematic review and metaanalysis to estimate potential recruitment to dementia intervention studies. Int J Geriatr Psychiatry. 2014;29(5):515-25.

15. Ries JD, Hutson J, Maralit LA, Brown MB. Group balance training specifically designed for individuals with Alzheimer disease: impact on Berg balance scale, timed up and go, gait speed, and mini-mental status examination. J Geriatr Phys Ther. 2015;38(4): 183-93.

16. Hoe J, Katona C, Roch B, Livingston G. Use of the QOL-AD for measuring quality of life in people with severe dementia-the LASER-AD study. Age Ageing. 2005;34(2):130-5.

17. Whitney SL, Wrisley DM, Marchetti GF, Furman JM. The effect of age on vestibular rehabilitation outcomes. laryngoscope. 2002; 112(10):1785-90. 